\title{
Evacuation Safety Evaluation in the Event of a Fire in a Shopping Center with a Connected Passageway in Korea
}

\author{
Seo-Young Kim ${ }^{1}$, Ha-Sung Kong*² \\ ${ }^{1 * 2}$ Fire and Disaster Prevention, WoosukUniversity Graduate Sch., WANJU, Korea \\ ppiony@naver.com ${ }^{1}, \underline{119 w s u @ \text { naver.com }^{2}}$
}

Article History: Received: 11 January 2021; Accepted: 27 February 2021; Published online: 5 April 2021

\begin{abstract}
In this study, scenarios were developed to evaluate evacuation safety in the event of a fire in a shopping center with a connected passageway and to reduce Required Safe Egress Time (RSET). The RSET for all occupants by scenario is as follows: The first scenario which used the general evacuation route took 20 minutes and 7 seconds. The second scenario which used the third floor's connected passageway for third and fourth floor, and using first floor entrance for first and second floor to evacuate took 14 minutes and 11 seconds. The evacuation time was 36 minutes and 52 seconds for scenario 3, which only used the fire escape stairs. The fourth scenario took 4 minutes and 19 seconds and used a connected passageway on every floor. Overall, this study shows that RSET for all occupants is reduced when a connected passageway is installed on every floor in shopping centers. Henceforth, more research is needed to determine whether connected passageway is a single firefighting object or a separate structure.
\end{abstract}

Keywords: Connected Passageway, Shopping Center, Evacuation Simulation, Required Safe Egress Time

\section{Introduction}

Large-scale buildings such as shopping centers with connected passageways are currently on the rise. Especially shopping centers are densely populated and visitors are not familiar with the layout of the building. Therefore, the number of casualties tends to increase in the event of a fire. For example, the fire at 00 bus terminal [1] in 00 province in South Korea on May 26, 2014 and the fire at Korea 00 Metapolis [2] on February 4, 2017 both had complicated building layouts because of the large size of the buildings and concentration of various facilities. In addition, there are a lot of inflammable products, so the progress of the fire is extremely fast in the event of a fire. In this situation, there will be panic and confusion in the rapid movement, so the RSET for all occupants will be increased along with the increasing risk of casualties.

Previous studies have been conducted by Lee Kang-young et al (2007) [3], Han Un-hee (2018)[4], AhnEunhee (2005)[5,23], Kim Won-guk et al (2018)[6], and Kim Hye-jin et al (2013)[7,24]. There were only simulations about buildings without connected passageways, while this study aims at evaluating efficient method of evacuation and safety by analyzing RSET for the two buildings with a connected passageway.

\section{Evacuation Simulation}

2.1 Object Selection and Outline of Evacuation Simulation

1) Object Selection of Evacuation Simulation

This study supposed that there was a fire in Building B in a shopping center consisting of buildings A and B and which is located in 00 city, 00 province in South Korea. The population density is high due to people and visitors moving between building A and B. Also, there are lots of people and the majority are unidentified people who are there to shop. Building B consists of parking lots from the second basement level to the first basement level, shopping malls on the first to fourth floor, a cinema on the fifth floor, and the sixth floor is used as a rooftop garden. As seen in Figure 1, the first floor to the fourth floor will be the focus of this study. conducted by applying the input values

Table. 1 Scenario Input Value

\begin{tabular}{|c|c|c|}
\hline Input Variable & Input Value & Reason \\
\hline Occupant Type & Children, Men, Women, Elderly & $\begin{array}{c}24 \text { month-12 year old children, 19-64 } \\
\text { year old adults, elderly over 65 years old } \\
{[8][9]}\end{array}$ \\
\hline Walking Speed & $1 \mathrm{~m} / \mathrm{s}$ & $\begin{array}{c}\text { Apply average walking speed ofpeople } \\
\text { who are unfamiliar with the layout of the } \\
\text { building[10] }\end{array}$ \\
\hline $\begin{array}{c}\text { Starting Time } \\
\text { of Evacuation }\end{array}$ & $\begin{array}{c}\text { Apply the time when all occupants in } \\
\text { the store are aware of the fire and begin to } \\
\text { evacuate[11] }\end{array}$ \\
\hline
\end{tabular}




\begin{tabular}{|c|c|c|}
\hline \multirow{3}{*}{ Shoulder Width } & Men : $39.8 \mathrm{~cm}[12]$ & \\
& Women : $35.7 \mathrm{~cm}[13]$ & Apply 'Size Korea (2015)' \\
& Children: $29.6 \mathrm{~cm}$ & \\
\hline
\end{tabular}

\section{Calculation Standard for Occupant Load}

The shopping center is a sales facility, and the occupant load was calculated based on the calculation standard according to the area per person for each floor. There are two sections; the first floor, which is a safety floor, and the second to fourth floors, which are considered as over second floors. The average daily visitor ratio was 21.5 percent for men, 60.3 percent for women, 10.2 percent for children, and 8 percent for elderly [14]. There were 1,630 people on the third floor, where the concentration was the highest. Table 2 shows the number of people [15] and the area per person on each floor.

Table 2. Calculation of Capacity \& Occupant Analysis

\begin{tabular}{|c|c|c|c|c|c|}
\hline Story & $\begin{array}{c}\text { Area per } \\
\text { Person }\left(\mathrm{m}^{2}\right)[16]\end{array}$ & $\begin{array}{c}\text { Floor } \\
\text { Space }\left(\mathrm{m}^{2}\right)\end{array}$ & $\begin{array}{l}\text { Occupant } \\
\text { Load }\end{array}$ & $\begin{array}{c}\text { Type } \\
\text { ofOccupant }\end{array}$ & $\begin{array}{l}\text { Number of } \\
\text { People (\%) }\end{array}$ \\
\hline \multirow{4}{*}{$1^{s t}$ floor } & \multirow{4}{*}{2.8} & \multirow{4}{*}{3,057} & \multirow{4}{*}{1,092} & Men & $235(21.5 \%)$ \\
\hline & & & & Women & $658(60.3 \%)$ \\
\hline & & & & Children & $112(10.2 \%)$ \\
\hline & & & & Elderly & $87(8 \%)$ \\
\hline \multirow{4}{*}{$2^{n d}$ floor } & \multirow{4}{*}{3.7} & \multirow{4}{*}{5,698} & \multirow{4}{*}{1540} & Men & $331(21.5 \%)$ \\
\hline & & & & Women & $929(60.3 \%)$ \\
\hline & & & & Children & $157(10.2 \%)$ \\
\hline & & & & Elderly & $123(8 \%)$ \\
\hline \multirow{4}{*}{$3^{r d}$ floor } & \multirow{4}{*}{3.7} & \multirow{4}{*}{6,032} & \multirow{4}{*}{1630} & Men & $351(21.5 \%)$ \\
\hline & & & & Women & $983(60.3 \%)$ \\
\hline & & & & Children & $166(10.2 \%)$ \\
\hline & & & & Elderly & $130(8 \%)$ \\
\hline \multirow{4}{*}{$4^{\text {th }}$ floor } & \multirow{4}{*}{3.7} & \multirow{4}{*}{5,842} & \multirow{4}{*}{1579} & Men & $340(21.5 \%)$ \\
\hline & & & & Women & $952(60.3 \%)$ \\
\hline & & & & Children & $161(10.2 \%)$ \\
\hline & & & & Elderly & $126(8 \%)$ \\
\hline
\end{tabular}

\subsection{Evacuation Scenario Composition}

Scenarios were organized into Scenario 1, Scenario 2, Scenario 3, and Scenario 4 to reduce the Required Safe Egress Time (RSET) for all occupants, as shown in Table 3. All scenarios assumed that no evacuation lifts were installed and that escalators were not used for fire routes. In addition, bottlenecks caused by dense population were considered in the evacuations, but delays caused by accidents were excluded. Scenario 1 consisted of evacuating via the general evacuation route from the actual drawing sheet used in this study to compare the general evacuation route with different conditions in the other scenarios. Scenario 2 consisted of using the third floor's connected passageway for the third and fourth floor, and using the first floor entrance for the first and second floor, assuming there is a fire on the second floor and it is therefore not possible to use the stairs connecting the second and third floor due to smoke. Scenario 3 consisted of evacuating using only enclosed stairways, assuming that the passageway on the third floor was used as an event hall and can therefore not be used to evacuate through. Scenario 4 is designed to allow evacuation from each floor by having a connecting passage installed on every floor to reduce the RSET for all occupants. The standard for measuring the evacuation time for each scenario was measuring when all the inhabitants have completed evacuated. The maximum exit distance for each scenario are as follows: Scenario 1: 253.3m, Scenario 2: $244.5 \mathrm{~m}$, Scenario 3: $418.1 \mathrm{~m}$ and 
Scenario 4: $143.7 \mathrm{~m}$. Scenario 4 has the shortest maximum evacuation distance, so it is assumed that the RSET is the shortest as well.

Table 3. Scenario Composition

\begin{tabular}{|c|c|c|c|c|}
\hline & Scenario1 & Scenario2 & Scenario3 & Scenario4 \\
\hline $\begin{array}{c}\text { Evacuati } \\
\text { on route }\end{array}$ & $\begin{array}{c}\text { Using } \\
\text { generalfire route }\end{array}$ & $\begin{array}{c}\text { 3rd and 4th floor: } \\
\text { 3rd floor's connected } \\
\text { passageway } \\
\text { 1st and 2nd floor: } \\
\text { 1st floor entrance }\end{array}$ & $\begin{array}{c}\text { Using only enclosed } \\
\text { stairway }\end{array}$ & $\begin{array}{c}\text { Having a connected } \\
\text { passageway on every } \\
\text { floor }\end{array}$ \\
\hline $\begin{array}{c}\text { Maximu } \\
\text { m exit } \\
\text { distance } \\
(\mathrm{m})\end{array}$ & 253.3 & 244.5 & 418.1 & 143.7 \\
\hline
\end{tabular}

2.3 Evaluation Basis

In evacuation facilities, most of the residents are always awake, but most of them are not familiar with the building's interior layout or escape route. In the event of an emergency, the facility broadcasts guidance from control rooms equipped with CCTV facilities. It was also confirmed by a trained fire protection manager that there is emergency broadcast equipment that can be recognized by all inhabitants in the building. The target site is a retail sales facility where food, clothing, and miscellaneous goods are sold, and the total floor area is over 1,000 square meters [17], so the evacuation time, as shown in Table 4, is set at less than two minutes [18].

Table 4. Available Evacuation Time for Occupancy

\begin{tabular}{|c|c|}
\hline Occupancy & $\begin{array}{c}\text { Available } \\
\text { evacuation } \\
\text { time }\end{array}$ \\
\hline $\begin{array}{c}\text { Store (Inhabitant is always awake but unfamiliar with the interior of the building } \\
\text { and the escape route) }\end{array}$ & Under 2 min \\
\hline
\end{tabular}

3. Conclusion and Consideration

The selected elapsed time intervals for recording the number of evacuees are 1 minute and 59 seconds, 5 minutes, 6 minutes and RSET for all occupants. The reason for having 1 minutes 59 seconds as one of the intervals is to check how many people have completed evacuation within the available evacuation time, where the available evacuation time is under 2 minutes at Table 4. Rescue workers normally arrive within 5 minutes of the fire alarm and begin rescuing people in the building [19]. It is required to check the number of people who evacuated in 6 minutes in the event of a fire since residents are estimated to have an evacuation time of approximately 6 minutes in the event of a fire in the USA.

\subsection{Scenario 1}

Figure 1 shows the number of successful evacuees by elapsed time when using the general fire route. 1,780 people (30.47\%) evacuated in 1 minute and 59 seconds, 3,756 (64.3\%) evacuated in 5 minutes, and 4,007 people $(68.6 \%)$ evacuated in 6 minutes. After 20 minutes and 7 seconds, all 5,841 people had evacuated. 


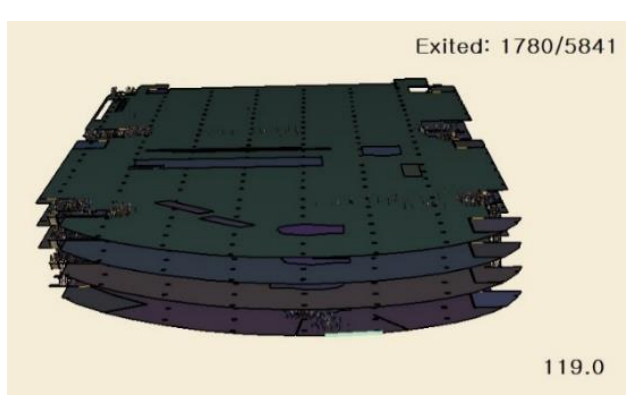

(a)

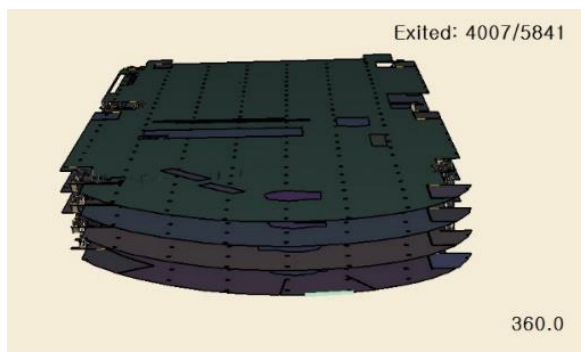

c)

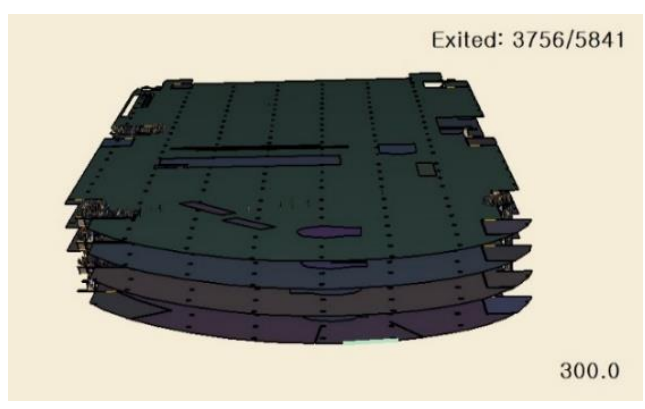

(b)

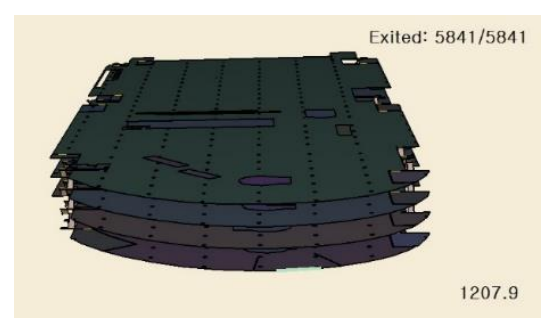

(d)

Figure 1. Change in the number of escapees by elapsed time in Scenario 1 (a) After 1 min59 s, (b) After 5 min, (c) After 6 min, (d) After 20 min 7 s(RSET for all occupants)

\subsection{Scenario2}

Figure 2 shows the number of successful evacuees by elapsed time when they used the third floor's connected passageway from the fourth floor to the third floor and the first floor entrance from the secondfloor to the first floor to evacuate. 1,857 people (31.79\%) evacuated in 1 minute and 59 seconds, 3,867 (66.2\%) evacuated in 5 minutes, and 4,496 people (76.97\%) evacuated in 6 minutes. After 14 minutes and 11 seconds, all 5,841 people had evacuated.

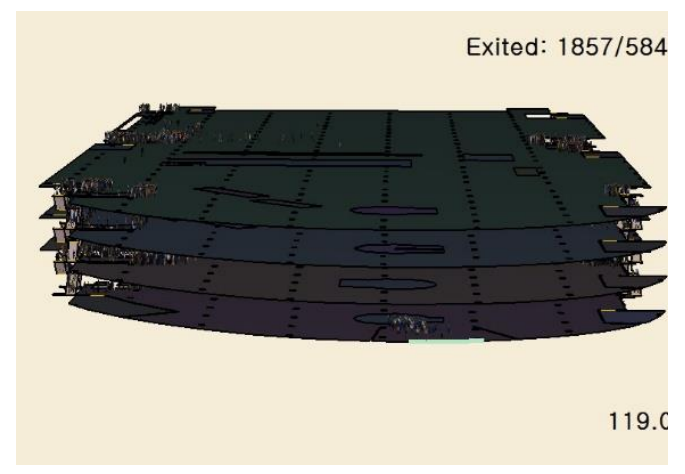

(a)

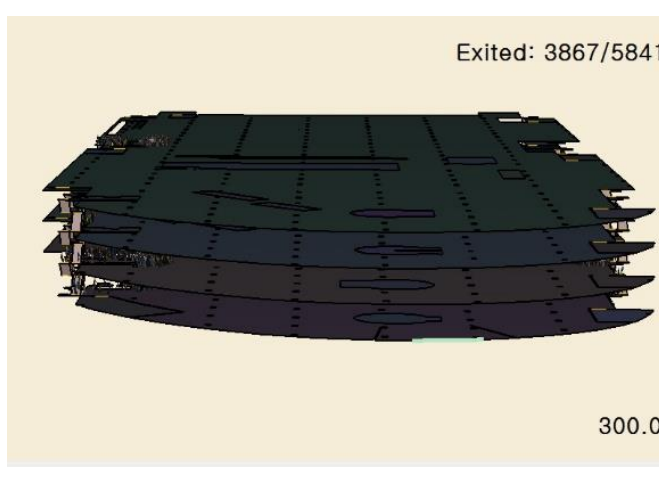

(b) 


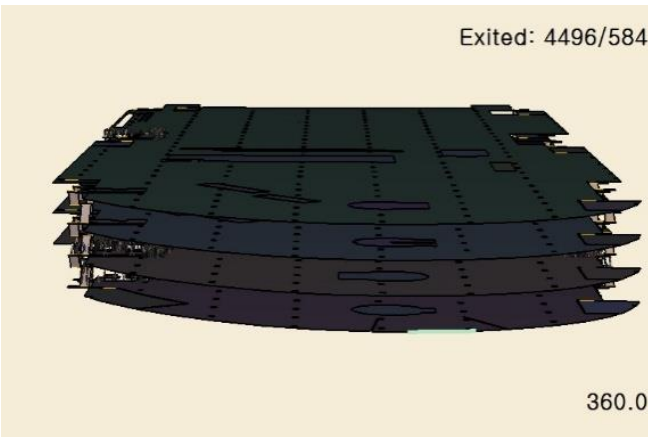

(c)

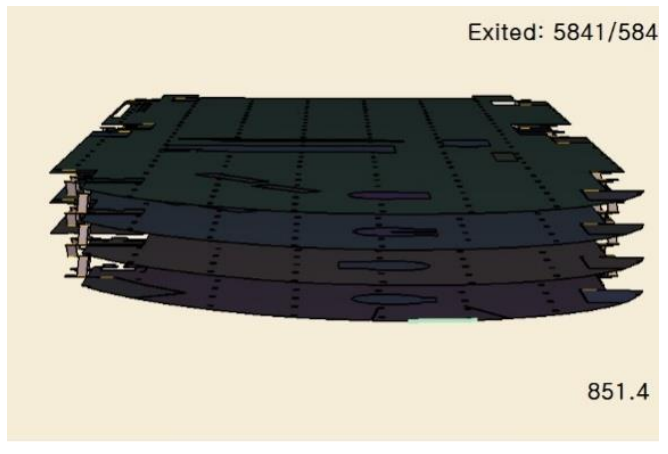

(d)

Figure 2. Change in the number of escapees by elapsed time in Scenario 2

(a) After 1 min $59 \mathrm{~s}$, (b) After 5 min, (c) After 6 min, (d) After 14 min 11 s(RSET for all occupants)

\subsection{Scenario 3}

Figure 3 shows the number of successful evacuees by elapsed time when they only used the fire escape stairs located between the first and fourth floors. 1,063 people (18.19\%) evacuated in 1 minute and 59 seconds, 1,659 (28.4\%) evacuated in 5 minutes, and 1,804 people (30.88\%) evacuated in 6 minutes. After 36 minutes and 52 seconds, all 5,841 people had evacuated.

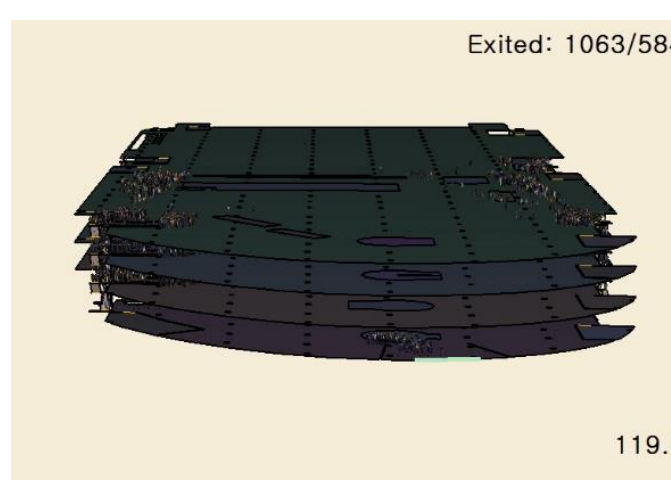

(a)

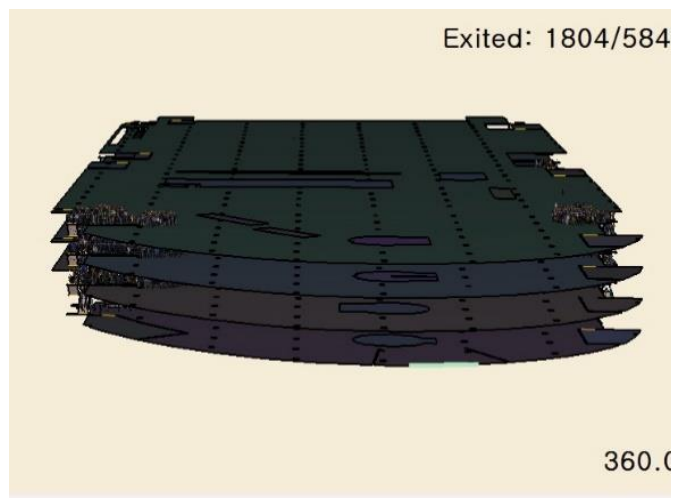

(c)

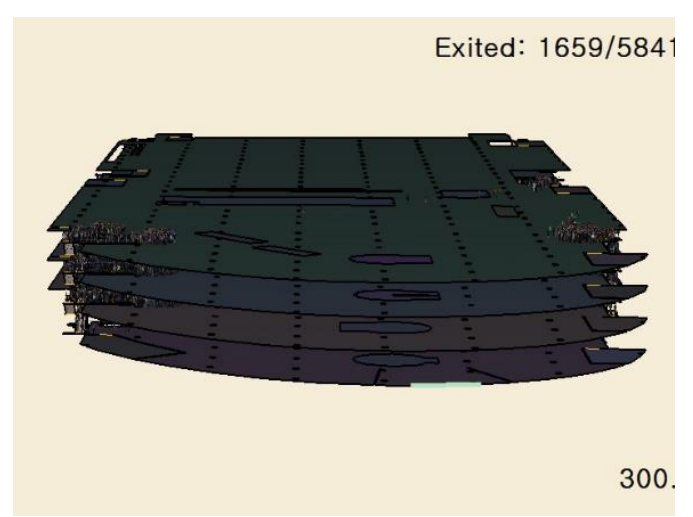

(b)

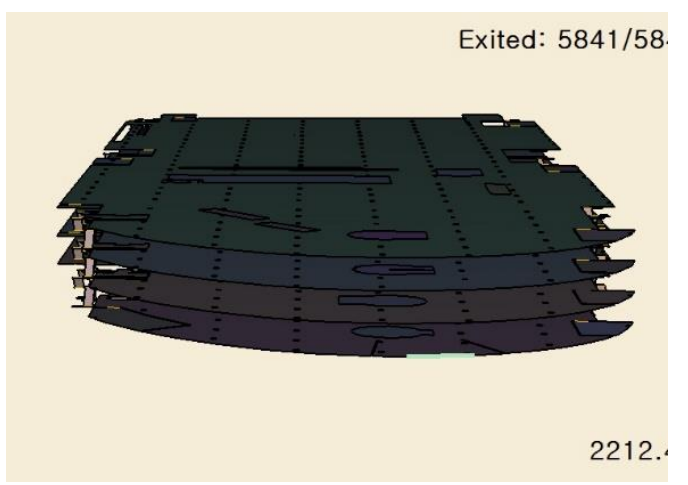

(d)

Figure 3. Change in the number of escapees by elapsed time in Scenario 3
(a) After $1 \min 59 \mathrm{~s}$,
(b) After $5 \mathrm{~min}$,
(c) After 6 min, (d) After 36 min52 s (RSET for all occupants)

\subsection{Scenario4}

Figure 4 shows the number of successful evacuees by elapsed time when connected passageways, which were only on the third floor, are installed on all floors to decrease RSET. 3,255 people (55.72\%) evacuated in 1 minute and 59 seconds, and the RSET for all 5,841 people was 4 minutes and 19 seconds. Even though this 
exceeds the evacuation time of 2 minutes, rescue workers normally arrive within 5 minutes of the fire alarm and immediately provide first aid and transport to the evacuated personnel, which can reduce casualties. It is also believed that all inhabitants will be evacuated within 6 minutes to avoid the life-threatening risk of fire.

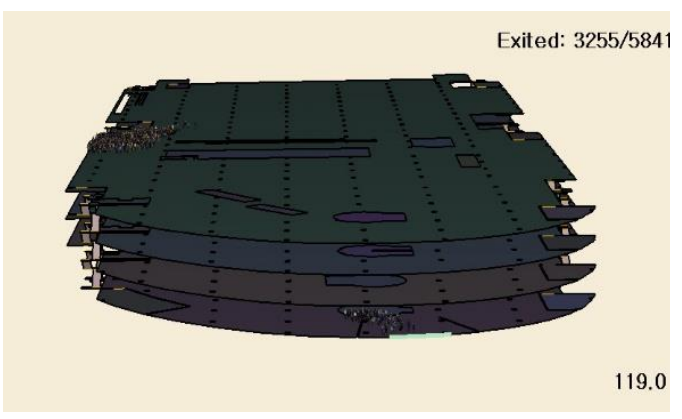

(a)

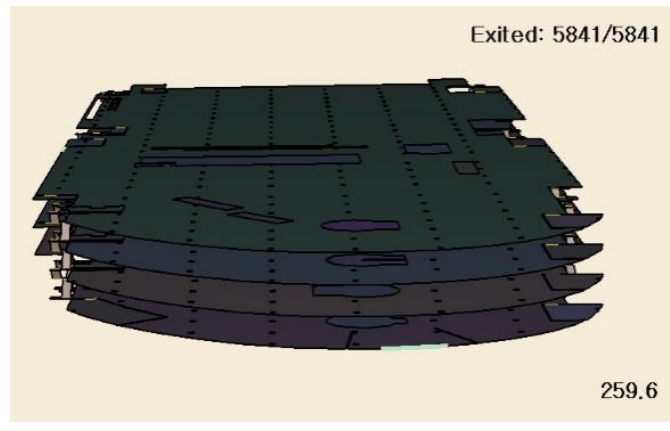

(b)

Figure 4. Change in the number of escapees by elapsed time in Scenario 4

(a) After $1 \min 59 \mathrm{~s}$, (b) After $4 \min 19 \mathrm{~s}$ (RSET for all occupants)

Analysis of scenario-specific RSETs, as shown in Table 5, showed that Scenario 4, which had a connected passageway on every floor, was 948.3 seconds less than Scenario 1, 591.8 seconds less than Scenario 2, and 1952.8 seconds less than Scenario 3. The result of Scenario 4 was an $88.4 \%$ decrease in RSET compared to Scenario 3, which was the longest. As a result, the RSET will be dramatically shortened if there is a connected passageway installed on every floor in a shopping center rather than having just one in the whole shopping center.

Table 5.The Number of People Evacuate by Elapsed Time in Each Scenario

\begin{tabular}{|c|c|c|}
\hline Scenario & Evacuation Time & Evacuee (people) \\
\hline \multirow{4}{*}{1} & $1 \min 59 \mathrm{~s}$ & 1,780 \\
\hline & $5 \mathrm{~min}$ & 3,756 \\
\hline & $6 \min$ & 4,007 \\
\hline & $\begin{array}{l}20 \text { min } 7 \mathrm{~s} \text { (RSET } \\
\text { for all occupants) }\end{array}$ & 5,481 \\
\hline \multirow{4}{*}{2} & $1 \min 59 \mathrm{~s}$ & 1,875 \\
\hline & $5 \mathrm{~min}$ & 3,867 \\
\hline & $6 \mathrm{~min}$ & 4,496 \\
\hline & $\begin{array}{l}14 \text { min } 11 \mathrm{~s} \text { (RSET } \\
\text { for all occupants) }\end{array}$ & 5,481 \\
\hline \multirow{4}{*}{3} & $1 \min 59 \mathrm{~s}$ & 1,063 \\
\hline & $5 \mathrm{~min}$ & 1,659 \\
\hline & $6 \mathrm{~min}$ & 1,804 \\
\hline & $\begin{array}{l}36 \text { min } 52 \mathrm{~s} \text { (RSET } \\
\text { for all occupants) }\end{array}$ & 5,481 \\
\hline \multirow[b]{2}{*}{4} & $1 \min 59 \mathrm{~s}$ & 3,255 \\
\hline & $\begin{array}{l}4 \text { min } 19 \mathrm{~s} \text { (RSET } \\
\text { for all occupants) }\end{array}$ & 5,481 \\
\hline
\end{tabular}

\section{Conclusion}

In this study, scenarios were developed to evaluate evacuation safety in the event of a fire in a shopping center with connected passageways and to reduce Required Safe Egress Time (RSET) for all occupants. The

results of the calculation of the number of evacuees according to the elapsed time are as follows:

1. Scenario 1: $30.47 \%$ of people escape in 1 minute and 59 seconds, $64.3 \%$ in 5 minutes, $68.6 \%$ in 6 minutes, and the RSET for all occupants was 20 minutes and 7 seconds.

2. Scenario 2: $31.79 \%$ of the people escape in 1 minute and 59 seconds, $66.2 \%$ in 5 minutes, $76.97 \%$ in 6 minutes, and the RSET for all occupants was 14 minutes and 11 seconds.

3. Scenario 3: $18.19 \%$ of people escape in a minute 59 seconds, $28.4 \%$ in 5 minutes, $30.88 \%$ in 6 minutes, 
and the RSET for all occupants was 36 minutes and 52 seconds.

4. Scenario 4: $55.72 \%$ of people escape in a minute 59 seconds, and the RSET for all occupants was 4 minutes and 19 seconds.

As a result of analyzing the RSET for all occupants by scenario, the fourth scenario which

had connected passageways installed on every floor showed a result $88.4 \%$ lower than scenario 3 , which has the longest RSET for all occupants. As a result, the RSET for all occupants will be dramatically shortened if there is a connected passageway installed on every floor in a shopping center. Henceforth, more research is needed to determine whether a connected passageway is a single firefighting object or a separate structure.

\section{References}

1. The Dong-A Ilbo, May 26, 2014.(https://www.donga.com/news/article/all/20140526/63760528/1)

2. The Dong-A Ilbo, February 4, 2017(https://bizn.donga.com/realestate/3/all/20170204/82713064/2/1

3. K.Y.Lee, H.J.Kim, W.K.Choi, S.J.Suh, "Analysis of the Evacuation Patterns aand Zoning in Department Store Fire", Journal of The Architectural Institute of Korea Planning \& Design, Vol.27, No.1, 2007, pp.1009-1010.

4. W.H.Han, "Study on Stagnation Factors Analysis and Improvement Methods through an Evacuation Experiment", Fire Science and Engineering, Vol.32, No.2, 2018, pp.57-58.

5. E.H.An, "A Study on Egress Routes Design Depending on Human Evacuation Behavior in Muti-Plex Theater", Journal of The Architectural Institute of Korea Planning \& Design, Vol.21, No.10, 2005, pp.131-138.

6. W.K.Kim, D.H.Seo, “A Study on Egress Algorithm for High-rise Buildings Using Egress Simulation”, Fire Science and Engineering, Vol.32, No.1,2018, p.33.

7. H.J,Kim, S.H.Lee, W.H.Hong, "Sensitivity Aalysis on the Staircase Evacuation Time for Occupant Input Attributes of Evacuation Simulation Tools: Focused on SIMULEX, buildingEXODUS, Pathfinder", Journal of The Architectural Institute of Korea Planning \& Design, Vol.29, No.11, 2013, pp.319-320.

8. Ministry of Food and Drug Safety, Guidance for Industry and Agency:Labeling for Drug Products Countent and Format, 2011, p.31.

9. Korea Ministry of Government Legislation, Article 4 of the Civil Code, March 7, 2011. Revision

10. M.DAVID.EGA, Concepts in Building Firesafety, giindangpublishing, 2003, pp.232 235.

11. Korea Ministry of Government Legislation, 「National Fire Safety Codes 202)」Article 4 Clause 11, 26 July 2017. Enforcement

12. Statistics Korea, Korean Body Size Survey : 120 areas of statistics (male),

13. (http://kosis.kr/statHtml/statHtml.do?orgId=115\&tblId=TX_115190170\&conn_path=I2)

14. Statistics Korea, Korean Body Size Survey : 120 areas of statistics (female),

15. (http://kosis.kr/statHtml/statHtml.do?orgId=115\&tblId=TX_115190171\&conn_path=I2

16. KoreaXX Shopping Center Internal Data

17. Y.M Bae, B.H Lee, S.W Cho, K.H Lee, The Evacuation Performance Review according to Vertical Circulation Arrangements, International Journal of Air-Conditioning and Refrigeration, 2018, p.396.

18. Korea Ministry of Government Legislation, Performance-oriented design methods and criteria such as fire protection system」[Appendix 1] No.3,26 July 2017. Enforcement

19. Korea Ministry of Government Legislation, 「Performance-oriented design methods and standards for fire-fighting facilities, etc. 」[Appendix 1] No.3,26 July 2017. Enforcement

20. Korea Ministry of Government Legislation, 「Act on Fire Prevention, Installation and Maintenance of Fire-Fighting Systems and Safety Control」」 [Appendix 2] No.5, June 26, 2018. Revision

21. Korea Ministry of Government Legislation, 「Act on Fire Prevention, Installation and Maintenance of Fire-Fighting Systems and Safety Control」[Appendix 2] relative height, No.2, No.3, June 26, 2018. Revision

22. M.S.Lee, Fire Safety Awareness and Assessment of Escape Methods by Residents in Apartment Building, Journal of the Architectural Institute of Korea, Vol.58, No.10, 2014,p.49.

23. Kaya, A., \& Aydin, Ö. (2019). E-Commerce In Turkey And Sap Integrated E-Commerce System.

24. Antoni, Z. L., Rootman, C., \&Struwig, F. W. (2019). The influence of Parental Financial Socialisation Techniques on Student Financial Behaviour. International Journal of Economics and Finance Studies, 11(2), 72-88. 